\title{
Antecedents of Intention to Use E-Learning
}

\author{
Khairudin $^{1,}$, Susi Herawati ${ }^{1}$, Desi Ilona $^{2}$ and Zaitul ${ }^{3^{*}}$ \\ ${ }^{1}$ Faculty of Teacher Trainning and Education, Universitas Bung Hatta, Padang, Indonesia \\ ${ }^{2}$ Faculty of Economics, Universitas Putra Indonesia YPTK, Padang, Indonesia \\ ${ }^{3}$ Faculty of Economics, Universitas Bung Hatta, Padang, Indonesia
}

\begin{abstract}
This study investigates the effect of Attitude toward e-learning, Facility condition, and Personalization on intention to use e-learning. theory of plan behaviour is used to understand the antecedents of intention to use e-learning. Using academic staffs as a research object and SEM-PLS, we conclude that Attitude toward e-learning and Personalization have a positive relationship with intention to use e-learning. However, Facility condition has a negative effect on intention to use e-learning. This study partially contributes to theory of plan behaviour. This finding also could be used by university to formulate e-learning concept by considering the significant antecedents in this study.
\end{abstract}

\section{Background of Study}

Higher Education Institution (HEI) has obtained remarkable opportunities indebted to the development of Information and Technology [1]. Reference [2] argue that there are two important ways by which we study and get information through Information technology (IT). First, IT enable us to conduct things more flexible, more efficiently, faster, and with substantial access for all. Next reason, Information technology permits us to carry out many of things that we cannot do know, or to do them in ways that are notably dissimilar. In fact, Information Technology creates an experience of learning in outside of curricula, classrooms, text-based formats to which we are customized [2]. In addition, it has been critical to assimilate information technology into e-learning in the era of knowledge economy. Reference [3- 4] state that there is increasing a dependency on the use of e-learning to ease learning and development in the workplace. The web-based application and internet technologies development in education serves unknown chances to aid lecturers effectively conveys the learning materials to students and teach every one, anytime and any places [5]. In fact, e-learning is worthwhile method because it has a low variable cost, flexible learning content, free of temporal and spatial constraints, and cost effectiveness [3]. [5] state that elearning is more pliable way for learning, and it is specifically convenient for persons with high self-control that allow them to acquire a knowledge at isolated places based on their own necessity.

E-learning requires the use of electronic media, such as the mobile phone, CD-ROM, internet, DVD, videotapes, television, etc. [6]. Universitas Bung Hatta is one of private universities located in west Sumatra, Indonesia. The IT Centre has developed the e-learning

*Corresponding author email: zaitul@bunghatta.ac.id 
system decade ago. However, it was not used optimally and usage rate was very low. A year ago, the IT Centre has been revised the system and use html-platform. No study has been done to see whether academic staffs are willing to use this system. However, the study of elearning has been done by many researchers in different location and context, such as [1-9].

From literature review of previous researches, there is a gap in literature, especially intention to use the e-learning system in private university in Indonesia. Therefore, the study in this subject would enrich the literature of Technology acceptance [10] and behaviour intention [11]. This study uses the attitude, facilitating condition, and personalization as antecedent of an intention to use the e-learning. These variables are selected due to inconclusive of previous studies findings. Therefore, this study aims to investigate the effect of these three variables on intention to use e-learning. The article is organized as follow. First session is background of study. Second session about methods and proceed to result and discussion. Final session is conclusion and recommendation.

\section{Method}

This study use an academic staff registered in Universitas Bung Hatta. Academic staffs are distributed a questioner using google form and share through WhatsApp (WA). For those using WA and registered as Gmail or google mail are expected to fill the questioners. This study applies the primary data gathering through survey. Intention to use e-learning is dependent variables and the independent variables are Attitude (Att), Facilitating Condition (Fas) and Personalization (Per). Intention to use e-learning was developed by [7]. Further, Attitude is measured by four items which developed based on [11] and adapted by [8]. Thus, facilitating condition use the items developed by [6], [12]. In addition, personalization use a measurement adapted by [7]. Data is measured by five-points Likert scales. The data analysed by using the smart-PLS. There are two model in smart-PLS: the measurement model and structural model [13]. Four criteria are used for measurement model [14]: (i) indicator reliability, (ii) internal consistency, (iii) convergent validity, and (iv) discriminant validity. Indicator validity applies the outer loadings and the value must be greater than 0.60 . In addition, internal consistency uses the composite reliability and Cronbach alpha and the value must be more than 0.70 . Thus, convergent validity utilizes the AVE and it must be greater than 0.50 . Finally, discriminant validity applied the Fornell-Lacker criterion and it should be more than its cross loading. Meanwhile, the structural model use two criteria [14]: predictive power, and predictive relevance. In addition, predictive power using R-square and higher value is better. Thus, predictive relevance uses Q-square and it must be greater than 0 . To answer the hypotheses, this study uses the significance of structural path coefficient [13].

\section{Result and discussion}

Final sample of this study is seventeen respondents. Demographic analysis is demonstrated in Table 1. Based on gender, male respondents are teen academic staffs or $58.82 \%$ and the rest are female $(41.18 \%)$. Respondent age is ranging from 31 to 53 years old. In addition, respondent with age 31 to 40 years old is about four respondents or $23.53 \%$, followed by 11 to 40 years old $(58.82 \%)$ and more than 50 years old (17.65\%). Based on faculty, academic staffs from economics, law, humanity, education and postgraduate are $11.76 \%, 5.88 \%, 5.88 \%, 23.53 \%, 23.53 \%$, and $29.41 \%$ respectively. Level of respondent education are $35.29 \%$ of doctorate and the rest are master holders. Academic position is tutor, lecturer and senior lecturer $(29.41 \%, 52.94 \%$, and $17.65 \%)$. 
Table 1. Demographic. Analysis

\begin{tabular}{cccc}
\hline Demographic & Category & Number & Percentage \\
\hline \multirow{2}{*}{ Gender } & Male & 10 & 58,82 \\
& Female & 7 & 41,18 \\
Age & 31 to 40 years & 4 & 23,53 \\
& 11 to 50 years & 10 & 58,82 \\
& $>$ 50 years & 3 & 17,65 \\
& Economics & 2 & 11,76 \\
& Law & 1 & 5,88 \\
Faculty & Humanity & 1 & 5,88 \\
& Education & 4 & 23,53 \\
& Civil Engineering & 4 & 23,53 \\
& PostGraduate & 5 & 29,41 \\
Education Level & Doctor & 6 & 35,29 \\
& Master & 11 & 64,71 \\
& Tutor & 5 & 29,41 \\
Position & Lecturer & 9 & 52,94 \\
& Senior Lecturer & 3 & 17,65 \\
\hline
\end{tabular}

\subsection{Analysis of Measurement model}

As mention above, there are four criteria used to analysis the measurement model. The result can be seen in Table 2. First analysis show that there are items having outer loading less than 0.60 and these items are excluded (att-4, per-2 and per-3). The analysis run again and the result indicate all outer loadings are greater than 0.6. second criteria is internal consistency and the result show that composite reliability and Cronbach alpha are satisfied, except for Personalisation, but still greater than 0.5 and it also has high composite reliability. Third criteria is convergent validity and it uses AVE. The value of AVE for all variables are greater than 0.5 and satisfied the requirement.

Table 2. Measurement Model

\begin{tabular}{ccllll}
\hline Construct & Item & Loadings & CA & CR & AVE \\
\hline \multirow{3}{*}{ Intention to Use } & iu_1 & 0,84 & & & \\
& iu_2 & 0,66 & 0,702 & 0.817 & 0,601 \\
& iu_3 & 0,82 & & & \\
Facility & fc_1 & 0,95 & & & \\
Condition & fc_2 & 0,97 & 0.935 & 0.953 & 0,836 \\
& fc_3 & 0,85 & & & \\
& fc_4 & 0,88 & & & \\
Attitude & at_1 & 0,64 & & & \\
& at_2 & 0,90 & & & \\
\multirow{2}{*}{ Personalisation } & at_3 & 0,83 & 0.758 & 0.836 & 0,635 \\
& pe_1 & 0,82 & & & \\
& pe_4 & 0,83 & 0.515 & 0.805 & 0,674 \\
\hline
\end{tabular}

Finally, discriminant validity uses the Fornel-Lacker criterion and the result satisfied the requirements (see Table 3). The coefficient correlation is created through square root of AVE (bold number). The value of coefficient correlation must be greater than the value of coefficient correlation with other construct. For example, coefficient correlation between Attitude (Att) is 0.797 and this value is greater than coefficient correlation between Attitude Facility (-0.257), Intention (0.560), and Personalization (0.351). therefore, it can be concluded that the construct has a good discriminant validity. The same explanation is also applied for other constructs. 
Table 3.Fornell-Lacker Criterion

\begin{tabular}{ccccc}
\hline Construct & Att & Fas & Int & Per \\
\hline Att & $\mathbf{0 . 7 9 7}$ & & & \\
Fas & -0.254 & $\mathbf{0 . 9 1 4}$ & & \\
Int & 0.560 & -0.568 & $\mathbf{0 . 7 7 5}$ & \\
Per & 0.351 & -0.223 & 0.735 & $\mathbf{0 . 8 2 1}$ \\
\hline
\end{tabular}

\subsection{Analysis of Structural Model}

The result of analysis of structural model could be seen in Table 4. There are two criteria in structural model analysis [14]: predictive power, and predicative relevance. Predictive power use R-square and its value should be higher, the higher the better. Meanwhile, the predictive relevance applies the Q-square and the cut-off value must be more than zero. The $t$ value of structural path coefficient is applied to see if any significant relationship between independent variables and dependent variable. The result show that R-square is 0.774 which means that intention to use e-learning is explained $77.4 \%$ by independent variables and the rest is explained by other variables which does not include in this study. Predicative relevance also indicates the value $(0.268)$ which is greater than zero and it, therefore, satisfy the requirement.

Table 4.Structural Model Analysis

\begin{tabular}{ccc}
\hline Endogenous Construct & R-Squared & Q-Squared \\
\hline Int & 0.774 & 0.268 \\
\hline Relation & Path Coefficient & T Value \\
\hline Att -> Int & 0.269 & 4.895 \\
Fas -> Int & -0.374 & 7.949 \\
Per -> Int & 0.554 & 13.594 \\
\hline
\end{tabular}

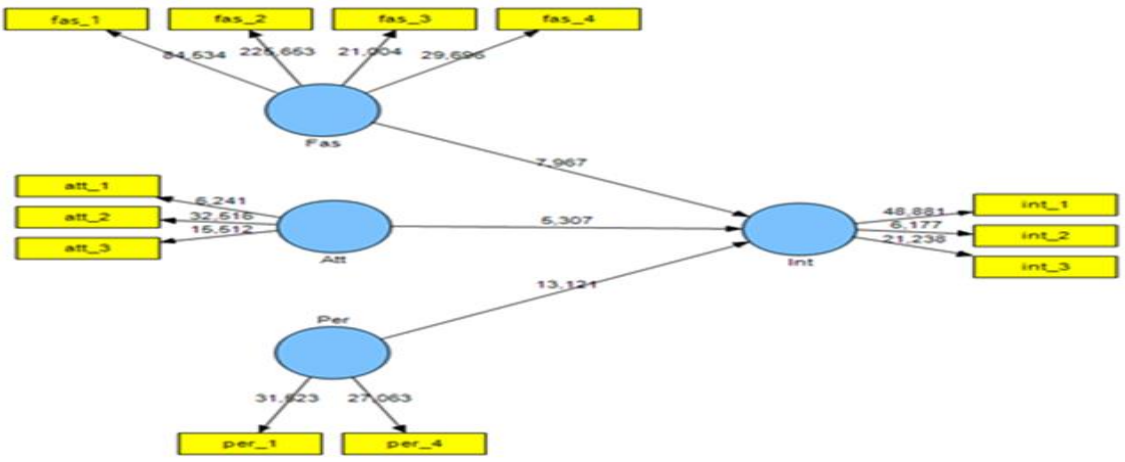

Fig 1. Structural model

The effect of Attitude, Facility condition and Personalization on intention to use e-learning could be seen from $t$-value and path coefficient. The Attitude has a positive relationship with intention to use e-learning due to the $t$ value of Attitude is greater than $1.96(\alpha=1 \%)$. Thus, it means that the higher the attitude toward e-learning, the higher the intention to use e-learning. This finding is consistent with the finding of $[8,9]$. The second finding is the significant effect of facility condition on the intention to use e-learning due to the $t$ value of this variable is greater than 1.96. Nevertheless, the relationship is negative which means that the better the facility condition, the lower the intention to use e-learning. This finding is not supported by [6] who conclude that there is a positive relationship between facility condition and intention to use e-learning. Personalization has a positive significant effect on the intention to use e- 
learning. this finding is alignment with the finding of [7]. The higher the Personalization, the higher the intention to use e-learning. the structural model is also demonstrated in Figure 2 below

\section{Conclusion and Recommendation}

Today higher education institution has been relying on e-learning to facilitate learning process. Many higher education institution has been used e-learning and other is starting to use it, such as Universitas Bung Hatta. However, it is not known how intention to use among academic staffs. Therefore, this study investigates the effect of attitude, facility condition and personalization on intention to use e-learning among academic staff in Universitas Bung Hatta. Using seventeen respondents and SEM-PLS, it is found that attitude and personalization have a positive effect on intention to use e-learning. However, facility condition has a negative relationship with intention to use e-learning. Theoretically, this study contributes to the theory of plan behaviour [11]. Practically, these findings could be used by higher education institution to formulate e-learning concept by considering Attitude, Facility condition and Personalization of user, such as academic staffs. Several limitations to this study need to be acknowledged. First, the sample size is too small. Second, this study use object in one higher education institution. Finally, the number of independent variables used in this study is limited to three variables. It is recommending that further research be undertaken in the following areas: (i) future research add sample size in order to gain more robust result, (ii) future research also can examine intention to use e-learning in other different higher education institution, and (iii) next study can add other variables from other perspective, such as from Technology Acceptance Model (TAM).

\section{References}

1 M. Ali, S. A. Raza, W. Qazi, C.-H. Puah, Interact. Technol. Smart Educ., 15, 1, ( 2018)

2 J. C. Roca, C. Chiu, F. J. Martinez, Int. J. Human-Computer Stud., 64, (2006).

3 K. Rui-Hsin, C.-T. Lin, Polic. an Int. J. police Strateg. Manag., 41, 1, (2018)

4 J. Fleming, K. Becker, C. Newton, Educ. Train., 59, 1, (2017)

5 Y. Zhang, Y. Fang, K. Wei, Z. Wang, Inf. Technol. People, 25, 4, ( 2012)

6 T. Teo, Campus-Wide Inf. Syst., 28, 2, ( 2011).

7 Y.-M. Cheng, Int. J. Web Inf. Syst., 10, 1, (2014).

8 R. Arteaga Sánchez, A. Duarte Hueros, M. García Ordaz, Campus-Wide Inf. Syst., 30, 2, (2013)

9 R. Cheung, D. Vogel, Comput. Educ., 63, ( 2013)

10 F. D. Davis, Int. J. Man-Machine Stud., 38, (1993)

11 I. Ajzen, Organ. Behav. Hum. Decis. Proccess, 50, (1991)

12 T. Teo, C. B. Lee, Campus-Wide Inf. Syst., 27, 2, (2010).

13 J. F. Hair, G. T. M. Hult, C. M. Ringle, M. Sarstedt, A Primer on Partial Least Squares Structural Equation Modeling (PLS-SEM). (Sage, 2013).

14 V. E. Vinzi, W. W. Chin, J. Henseler, H. Wang, Handbook of Partial Least Square: Concepts, Methods and Applications. (Springer, 2010). 